\title{
Drotaverine hydrochloride versus valethamate bromide for cervical dilatation in labour: a comparative study
}

\author{
Deepshikha $^{1}$, Monica Soni ${ }^{1 *}$, Deepak Gupta ${ }^{2}$, Santosh Godara ${ }^{1}$
}

\begin{abstract}
${ }^{1}$ Department of Obstetrics and Gynecology, PBM Hospital Bikaner, Rajasthan, India
${ }^{2}$ Department of Radiodiagnosis, JLN Medical College Ajmer, Rajasthan, India
\end{abstract}

Received: 18 February 2020

Revised: 21 March 2020

Accepted: 27 March 2020

\author{
*Correspondence: \\ Dr. Monica Soni, \\ E-mail: drmonikasoni3008@gmail.com
}

Copyright: (c) the author(s), publisher and licensee Medip Academy. This is an open-access article distributed under the terms of the Creative Commons Attribution Non-Commercial License, which permits unrestricted non-commercial use, distribution, and reproduction in any medium, provided the original work is properly cited.

\begin{abstract}
Background: Labor is the most perilous journey a woman has to undertake. Painless and short labor is desired by every woman and is a constant aim for obstetrician. Objective of this study was to compare the efficacy of drotaverine hydrochloride with valethamate bromide for cervical dilatation in labor in primigravida.

Methods: The present study was conducted in the department of obstetrics and gynecology, S. P. Medical College and Associated Group of Hospitals, Bikaner, Rajasthan from $1^{\text {st }}$ August 2018 to $31^{\text {st }}$ July 2019 over a period of 1 year. Total of 300 patients were included in the study with 150 patients in each of the two groups. In this study the effects of Drotaverine hydrochloride (Group A) and Valethamate bromide (Group B) on cervical dilatation were compared.

Results: In our study, the mean drug delivery interval was 101.58 \pm 78.06 mins in Group A and 134.24 \pm 94.12 mins in Group B. The mean number of doses of drug required was $1.27 \pm 0.55$ in Group A and $4.17 \pm 1.62$ in Group B. The difference was statistically highly significant $(\mathrm{p}<0.001)$.

Conclusions: Drotaverine hydrochloride is found to be better than valethamate bromide in shortening the duration of active phase of labor in primigravidae. Drotaverine was found to be a better drug, hence, can be used to reduce the agony of the laboring woman without any significant side effects on the mother or the fetus.
\end{abstract}

Keywords: Labor, Drotaverine, Valethamate (epidosin)

\section{INTRODUCTION}

Labour is one of the most important episodes in the life of women. In the process of labour, the duration of labour has great influence on both maternal and perinatal morbidity. In modern times, "active management" trends towards curtailing the total duration of labour compatible with the safety of the mother and foetus. ${ }^{1}$ The first stage of labour in a primigravida lasts about 12-16 hours and in a parous woman 6-8 hours. Active labour can be reliably diagnosed when cervical dilatation is $4 \mathrm{cms}$ or more in presence of effective uterine contractions. Once this cervical dilatation threshold is reached, normal progress in delivery can be expected, depending on parity, in ensuing 4-6 hours or so. ${ }^{2}$ Prolonged labour has always been a problem for obstetricians. Prolonged labour lead to high feto-maternal morbidity and increase the incidence of operative deliveries. Thus, shortening the duration of labour without jeopardizing fetal and maternal interest has been warranted. Many times, it is observed that in spite of good uterine contractions; cervix fails to dilate or dilates very slowly. This is functional cervical dystocia. Methods that aim at minimizing the incidence of functional cervical dystocia and cutting short the first stage of labour are welcome by both obstetricians and parturient women It has been proved that cervical 
dilatation is one of the important factors which determine the duration of labor. Various drugs have been tried to hasten the cervical dilatation and minimize the pain without increasing maternal or perinatal mortality and morbidity. The present study was undertaken to evaluate and compare the role of two different drugs on cervical dilatation in labour. In this study the effects of drotaverine hydrochloride (Group A) and valethamate bromide (Group B) were compared.

\section{Drotaverine hydrochloride}

Mechanism of action: Drotaverine is an isoquinoline derivative, inhibits specifically phosphodiesterase IV (PDE IV) which in turn increases the intracellular concentration of cAMP and cGMP and causes smooth muscle relaxation. ${ }^{3}$

Dosage: Drotaverine is available in form of tablet and injection (I/V or I/M). Inj. drotaverine hydrochloride 40 $\mathrm{mg}$ is given intramuscularly at an interval of 2 hours up to a maximum 3 injections.

Metabolism: It is readily metabolized in the liver by odeethylation to mono- and di-phenolic compounds and their corresponding glucuronic acid derivative. ${ }^{4}$

Excretion: Drotaverine is metabolized in liver and it is excreted in the urine and faeces. The half-life of drotaverine is approximately $7-12$ hours. $^{5}$

Side effect: Drotaverine has no serious adverse effect and is well tolerated by all age group. In rare cases headache, nausea, vertigo, hypotension may occur.

\section{Valethamate bromide}

Valethamate is a mixture of diphenylpiperidino-propane ethylaisamide HCL.

Mechanism of action: The main action of epidosin is anticholinergic. It acts on smooth muscle of internal organ. It has atropine like parasympatholytic action. The drug reduces the hyperexcitability of parasympathetic system and lowers the spasm of smooth muscle system. ${ }^{6}$

Dosage: Each ampoule of valethamate bromide $8 \mathrm{mg}$ is given intravenously at an interval of $30 \mathrm{~min}-1$ hour up to maximum 6 injections. $^{7}$

Side effect: The common side effect with the use of epidosin are dryness of mouth, flushing of skin, elevation of body temperature, transient tachycardia, blurred vision, headache, vomiting, allergy or idiosyncratic reaction like urticaria or drug rashes.

Aim of this study was to compare the efficacy of drotaverine hydrochloride with valethamate bromide for cervical dilatation in labor in primigravida.

\section{METHODS}

The present prospective randomized clinical trial was conducted in the department of obstetrics and gynecology, S. P. Medical College and Associated Group of Hospitals, Bikaner, Rajasthan, India over a period of 1 year from $1^{\text {st }}$ August 2018 to $31^{\text {st }}$ July 2019. Total 300 women were enrolled in the study after fulfilling the inclusion and exclusion criteria.

Proper counselling was done and written informed consent was taken. A detailed history was taken including age, duration of marriage, menstrual pattern and any history of excessive weight gain, swelling of feet, epigastric pain, oliguria, blurring of vision etc.

\section{Inclusion criteria}

- $\quad$ Singleton term pregnancy

- Cephalic presentation

- Willingness to participate in the study

- Regular established uterine contractions at the rate of $\geq 12$ contractions per hour, each contraction lasting for at least 30-40 seconds ${ }^{8}$

- Cervical dilatation of $\geq 3-4 \mathrm{~cm}$ and $>50 \%$ effaced with favorable bishop score

- Intact fetal membranes

- Primigravida

- $\quad$ Age between 18 to 35 years.

\section{Exclusion criteria}

- Malpresentation

- Twin pregnancy

- Cervical surgery in the past or a history of cervical injury

- Maternal medical disorders

- Known hypersensitivity to drotaverine or valethamate

- if any other spasmolytic agent had been used within 48 hours

- $\quad$ Evidence of fetal or maternal distress

- Absolute indication for cesarean section

- Unwillingness to participate in the study

- Grand multipara.

\section{Data collection}

Cases eligible for study were randomly enrolled in study Group A and B.

Group A: Cases where injection drotaverine containing $40 \mathrm{mg}$ was administered intravenously during active phase of labor at an interval of 2 hours up to a maximum of 3 injections

Group B: Cases where injection valethamate containing $8 \mathrm{mg}$ was administered intravenously in active phase of 
labour at intervals of 30 minutes up to a maximum of 6 injections.

Vital parameters were monitored and progress of labour was assessed. Close watch on fetal heart rate was kept. Injection delivery interval, mode and time of delivery were noted Apgar at 1 and 5 minutes after birth and NICU admission was noted. Mode of delivery, maternal and fetal outcome was compared to know the efficacy of drotaverine and valethamate on cervical dilatation and in shortening the duration of active stage of labor.

\section{Statistical analysis}

To collect required information from eligible patients, a pre-structured pre-tested proforma was used. Data was systematically analyzed with the help of frequencies, figures, proportions, appropriate statistical test as required.

\section{RESULTS}

The present study was carried out in 300 parturient women. In this study, the majority of subjects were between 21-25 years of age in both the groups. The mean maternal age was $22.08 \pm 2.83$ years in Group A and $22.00 \pm 2.72$ years in Group $\mathrm{B}$ making the groups comparable for age.

The mean period of gestation was $38.62 \pm 1.02$ and $38.41 \pm 0.96$ weeks in Group A and Group B respectively which was comparable. The mean Bishop Score in group A was $10.75 \pm 1.39$ while in Group B it was $10.43 \pm 1.60$ and the difference was found statistically insignificant ( $\mathrm{p}$ $>0.05$ ) and the both groups were comparable for study.

Table 1: Distribution of cases according to baseline characteristic.

\begin{tabular}{|llll|}
\hline \multicolumn{2}{|l}{ Baseline characteristic } & Mean & SD \\
\hline \multirow{2}{*}{ Age (years) } & Group A & 22.08 & 2.03 \\
\cline { 2 - 4 } & Group B & 22.00 & 2.72 \\
\hline \multirow{2}{*}{ Gestational age } & Group A & 38.62 & 1.02 \\
\cline { 2 - 4 } & Group B & 38.41 & 0.96 \\
\hline \multirow{2}{*}{ Bishop score } & Group A & 10.75 & 1.39 \\
\cline { 2 - 4 } & Group B & 10.43 & 1.60 \\
\hline
\end{tabular}

Table 2: Distribution of cases according to injection delivery interval (IDI).

\begin{tabular}{|c|c|c|c|c|c|c|}
\hline \multirow{2}{*}{ IDI (min) } & \multicolumn{2}{|c|}{ Group A (n=150) } & \multicolumn{2}{|c|}{ Group B (n=150) } & \multicolumn{2}{|c|}{ Total } \\
\hline & No. & $\%$ & No. & $\%$ & No. & $\%$ \\
\hline$<120$ & 102 & $68.0 \%$ & 77 & $51.3 \%$ & 179 & $59.7 \%$ \\
\hline $120-240$ & 29 & $19.3 \%$ & 51 & $34.0 \%$ & 80 & $26.7 \%$ \\
\hline$>240$ & 19 & $12.7 \%$ & 22 & $14.7 \%$ & 41 & $13.7 \%$ \\
\hline Mean \pm SD & \multicolumn{2}{|c|}{$101.58 \pm 78.06$} & \multicolumn{2}{|c|}{$134.24 \pm 94.12$} & & \\
\hline $\mathrm{p}$ value & $<0.0$ & & & & & \\
\hline
\end{tabular}

Table 3: Distribution of cases according to number of doses of drug administered.

\begin{tabular}{|c|c|c|c|c|c|c|}
\hline \multirow{2}{*}{ Doses of Drug } & \multicolumn{2}{|c|}{ Group A (n=150) } & \multicolumn{2}{|c|}{ Group B (n=150) } & \multicolumn{2}{|c|}{ Total } \\
\hline & No. & $\%$ & No. & $\%$ & No. & $\%$ \\
\hline 1 & 117 & $78.0 \%$ & 3 & $2.0 \%$ & 120 & $40.0 \%$ \\
\hline 2 & 26 & $17.3 \%$ & 30 & $20.0 \%$ & 56 & $18.7 \%$ \\
\hline 3 & 7 & $4.7 \%$ & 27 & $18.0 \%$ & 34 & $11.3 \%$ \\
\hline 4 & 0 & - & 20 & $13.3 \%$ & 20 & $6.7 \%$ \\
\hline 5 & 0 & - & 19 & $12.7 \%$ & 19 & $6.3 \%$ \\
\hline 6 & 0 & - & 51 & $34.0 \%$ & 51 & $17.0 \%$ \\
\hline Mean \pm SD & \multicolumn{2}{|l|}{$1.27 \pm 0.54$} & \multirow{2}{*}{\multicolumn{2}{|c|}{$4.17 \pm 1.62$}} & & \\
\hline $\mathrm{p}$ value & $<0.001$ & & & & & \\
\hline
\end{tabular}

Table 4: Distribution of cases according to mode of delivery.

\begin{tabular}{|c|c|c|c|c|c|c|}
\hline \multirow{2}{*}{ Mode of delivery } & \multicolumn{2}{|c|}{ Group A $(\mathrm{n}=\mathbf{1 5 0})$} & \multicolumn{2}{|c|}{ Group B $(n=150)$} & \multicolumn{2}{|c|}{ Total } \\
\hline & No. & $\%$ & No. & $\%$ & No. & $\%$ \\
\hline LSCS & 5 & $3.3 \%$ & 7 & $4.7 \%$ & 12 & $4.0 \%$ \\
\hline NVD & 145 & $96.7 \%$ & 141 & $94.0 \%$ & 286 & $95.3 \%$ \\
\hline Forceps & 0 & - & 2 & $1.3 \%$ & 2 & $0.7 \%$ \\
\hline $\mathrm{p}$ value & 0.303 & & & & & \\
\hline
\end{tabular}


As shown in the Table 2, 68\% subjects delivered within 120 mins ( 2 hours) of administration of drug in Group A as compared to $51.3 \%$ in Group B. The mean drug delivery interval was $101.58 \pm 78.06$ mins in Group A and 134.24 \pm 94.12 mins in Group B. The difference was statistically highly significant $(p<0.001)$. The mean requirement of drug in Group A was $1.27 \pm 0.55$ doses whereas in Group B it was $4.17 \pm 1.62$ doses and this difference was found statistically highly significant ( $p$ $<0.001)$. As shown in the Table $4,96.7 \%$ subjects in Group A and $94 \%$ in Group B had normal vaginal delivery. The difference was statistically insignificant ( $\mathrm{p}$ $>0.05)$.
Study observed that in Group A, 2.7\% subjects complained of tachycardia, $1.3 \%$ developed headache and $0.7 \%$ had dryness of mouth. $3.3 \%$ patients had cervical tear, $2 \%$ cases had nausea/vomiting, $1.3 \%$ cases had impaired alertness, $2 \%$ cases had vertigo while 0.7 cases had blurred vision.

In Group B $4.0 \%$ patient had complained of tachycardia and dryness of mouth, $2 \%$ cases had cervical tear, $3.3 \%$ cases had nausea/vomiting, $2 \%$ cases had impaired alertness and blurred vision and $3.3 \%$ cases had vertigo.

Table 5: Distribution of cases according to side effects.

\begin{tabular}{|lllllll|}
\hline \multirow{2}{*}{ Side effect } & Group A $(\mathbf{n = 1 5 0}$ & \multicolumn{2}{l}{ Group B $(\mathbf{n = 1 5 0}$} & \multicolumn{2}{l|}{ Total } \\
\hline Tachycardia & No. & $\mathbf{\%}$ & No. & $\mathbf{\%}$ & No. & $\mathbf{\%}$ \\
\hline Dryness of mouth & 4 & $2.7 \%$ & 6 & $4.0 \%$ & 10 & $3.3 \%$ \\
\hline Headache & 1 & $0.7 \%$ & 6 & $4.0 \%$ & 7 & $2.3 \%$ \\
\hline Flushing of face & 2 & $1.3 \%$ & 0 & & 2 & $0.7 \%$ \\
\hline Rise in temperature & 0 & - & 0 & - & 0 & - \\
\hline Cervical tear & 0 & - & 0 & - & 0 & - \\
\hline Nausea/vomiting & 5 & $3.3 \%$ & 3 & $2.0 \%$ & 8 & $2.7 \%$ \\
\hline Impaired alertness & 3 & $2.0 \%$ & 5 & $3.3 \%$ & 8 & $2.7 \%$ \\
\hline Vertigo & 2 & $1.3 \%$ & 3 & $2.0 \%$ & 5 & $1.7 \%$ \\
\hline Blurred vision & 3 & $2.0 \%$ & 5 & $3.3 \%$ & 8 & $2.7 \%$ \\
\hline
\end{tabular}

Table 6: Distribution of cases according to Apgar score at 5 minuteS.

\begin{tabular}{|c|c|c|c|c|c|c|}
\hline \multirow{2}{*}{ Apgar score } & \multicolumn{2}{|c|}{ Group A $(n=150)$} & \multicolumn{2}{|c|}{ Group B $(n=150)$} & \multicolumn{2}{|c|}{ Total } \\
\hline & No. & $\%$ & No. & $\%$ & No. & $\%$ \\
\hline 7 & 9 & $6.0 \%$ & 9 & $6.0 \%$ & 18 & $6.0 \%$ \\
\hline 8 & 8 & $5.3 \%$ & 9 & $6.0 \%$ & 17 & $5.7 \%$ \\
\hline 9 & 133 & $88.7 \%$ & 132 & $88.0 \%$ & 265 & $88.3 \%$ \\
\hline Mean \pm SD & \multicolumn{2}{|c|}{$8.83 \pm 0.51$} & \multicolumn{2}{|c|}{$8.82 \pm 0.52$} & & \\
\hline $\mathrm{p}$ value & \multicolumn{2}{|c|}{0.911} & & & & \\
\hline
\end{tabular}

Majority of neonates had Apgar scores 9 in both the groups. Mean Apgar $8.83 \pm 0.51$ and $8.82 \pm 0.52$ at 5 minutes in Group A and B respectively and the difference was found insignificant $(\mathrm{p}>0.05)$.

\section{DISCUSSION}

Labor is one of the most important events in a woman's life. Prolonged labor has implications for both the mother and the fetus. Reducing the length of labor is a highly desirable goal of intrapartum care, from the perspective of both maternal and fetal well-being. ${ }^{9}$ Cervical dilatation is one of the important factors which determines the duration of labor and is resultant of all driving forces of uterine contractions acting against passive tissue resistance. ${ }^{10}$ Cervical ripening, expressed as remodeling of the cervical connective tissue, has been proved to be necessary for an uncomplicated vaginal delivery. ${ }^{11}$ In this study, the age of patients was between 20-35 years. Mean age of subjects in Group A was 22.08 \pm 2.83 years while in Group B, it was 22.00 \pm 2.72 years. There was no statistically significant difference of age distribution between the two groups and both the groups were comparable for study. In this study, the maximum number of patients belonged to the age group 21-25 years. This was comparable to the studies done by Sharma et al, Nagaria et al, Kaur et al, Naga et al, Kalhon et al, Edessy et al and Patil et al and related to the average age of marriage and child bearing in study area. ${ }^{12-18}$

In this study, majority of cases in both the groups were unbooked. They were $67.3 \%$ in Group A and $73.3 \%$ in Group B. The difference was found statistically insignificant ( $p>0.05$ ) and both the groups were comparable for study. This was comparable to the studies 
done by Sharma et al, Nagaria et al, Kaur et al, Naga et al, Kalhon et al, Edessy et al and Patil et al. ${ }^{12-18}$

The mean gestational age of the subjects in this study was $38.56 \pm 1.02$ weeks in Group A and 38.69 \pm 0.90 weeks in Group B. The mean gestational age was similar in the studies conducted by Sharma et al, Nagaria et al, Kaur et al, Naga et al, Kalhon et al, Edessy et al and Patil et al and related to the inclusion criteria involved and average gestational age for delivery in study area. ${ }^{12-18}$

Mean Bishop score in Group A was $10.75 \pm 1.39$ while in Group B, it was $10.43 \pm 1.60$ and the difference was found statistically insignificant $(\mathrm{p}>0.05)$ and the both groups were comparable for study. This was comparable to the studies done by Sharma et al, Nagaria et al, Kaur et al, Naga et al, Kalhon et al, Edessy et al and Patil et al. ${ }^{12-18}$ Similar Bishop's score was kept in inclusion criteria to rule out confounding factors at the initiation of drug administration and results.

\section{Table 7: Comparison of drug delivery interval of different.}

\begin{tabular}{|c|c|c|}
\hline STUDY & $\begin{array}{l}\text { Group A } \\
\text { (minutes) }\end{array}$ & $\begin{array}{l}\text { Group B } \\
\text { (minutes) }\end{array}$ \\
\hline Sharma et al ${ }^{12}$ & $194 \pm 57.04$ & $220.7 \pm 86.12$ \\
\hline Nagaria et al ${ }^{13}$ & $135.87 \pm 85.94$ & $200.13 \pm 15.04$ \\
\hline Madhu et al ${ }^{19}$ & 183.2 & 206.5 \\
\hline Dahal et $\mathrm{al}^{20}$ & $192.56 \pm 75.47$ & $249.13 \pm 88.32$ \\
\hline Selvaraj et al ${ }^{21}$ & $219.6 \pm 37.9$ & $274.84 \pm 29.09$ \\
\hline Nishty $^{22}$ & $116.34 \pm 59.44$ & $158.78 \pm 58.98$ \\
\hline Mandal $^{23}$ & $190.92 \pm 38.96$ & $209.80 \pm 45.13$ \\
\hline Present study & $101.58 \pm 78.06$ & $134.24 \pm 94.12$ \\
\hline
\end{tabular}

In this study, the mean drug delivery interval was 101.58 \pm 78.06 mins in Group A and 134.24 \pm 94.12 mins in Group B. The difference was statistically highly significant $(p<0.001)$. Drotaverine hastens the process of labor as compared to other drugs as seen in the studies of other authors like Selvaraj et al, Madhu et al, Sharma et al and Nagaria et al, Nishty et al, Mandal and Molla. ${ }^{12,13,19,21,23}$

Sharma et al, in their study reported that drotaverine accelerated labor more rapidly and was associated with lesser side effects. ${ }^{12}$ The rate of cervical dilatation was highest in the drotaverine hydrochloride group (2.04 $\mathrm{cm} /$ hour) compared with the valethamate bromide group $(1.86 \mathrm{~cm} /$ hour$)$ and control group $(1.01 \mathrm{~cm} / \mathrm{hour})$. In the present study when drotaverine was given in 3 doses 2 hours apart the result was better than when given in a single dose by Sharma et al. ${ }^{12}$

Selvaraj and Natarajan compared the effect of drotaverine hydrochloride and valethamate bromide on cervical dilatation in 150 primigravidae. ${ }^{21}$ Drotaverine was found to be 2 times more potent and superior than valethamate in achieving faster cervical dilatation and shortening of the first stage of labor with fewer side effects in the mother and fetus which is comparable to this study.

Mandal and Molla study, in their study reported that the mean duration of active phase of labour in drotaverine group was $123.12 \pm 37.82$ and $102.75 \pm 36.90 \mathrm{~min}$ in primigravida and multigravida respectively whereas in valethamate group results were $156.30 \pm 45.10$ and $139.98 \pm 45.89$ min respectively. ${ }^{23}$ There was a statistically significant reduction in the duration of active phase of labor in both primigravida and multigravida given drotaverine when compared with valethamate bromide. Drotaverine was significantly more effective than valethamate ( $\mathrm{p}<0.0001)$. The results were comparable to present study. The drug delivery interval was slightly better with valethamate bromide in the present study as compared to when the drugs were given in the studies of like Selvaraj et al, Madhu et al, Sharma et al and Nagaria et al, Nishty et al, Mandal and Molla. ${ }^{12,13,19,21-23}$ The sample size in the studies of Madhu et al and Dahal et al were small, but drotaverine was found to have a shorter drug delivery interval than the other group. ${ }^{19,20}$

As seen in the present study, 96.7\% subjects in Group A and $94 \%$ in Group B had normal vaginal delivery. LSCS was done for 5 subjects in Group A and 7 subjects in Group B and 2 subjects had forceps delivery in Group B. The difference was found statistically insignificant ( $p$ $>0.05$ ). Dahal et al, in their study reported $96 \%$ cases delivered normally, $2 \%$ underwent LSCS and also $2 \%$ underwent for instrumental delivery in Group B which is comparable to present study. ${ }^{15}$ The results were comparable to those of other authors as Kalhon et al, Patil et al, Selvaraj et al, Mandal and Molla. ${ }^{16,18,21,23}$

Drugs used in the study are known to cause minor side effects in the mother. In this study only $2.7 \%$ cases in the drotaverine group had tachycardia as compared to $4 \%$ in valethamate group. Sharma et al, Nagaria et al, Dahal et al, Patil et al, Mandal and Molla in their studies also reported significantly higher incidence of tachycardia in the valethamate group $(20 \%, 22 \%, 21 \%, 28 \%, 9 \%$ respectively). ${ }^{12,13,18,20,23}$ All the side effects were minor, did not need specific treatment and subsided on their own in this study as also reported by Sharma et al, Nagaria et al, Dahal et al, Patil et al, Mandal and Molla. ${ }^{12,13,18,20,23}$

In the present study there was no incidence of adverse Apgar score in either group related to drug given. In Group B, there were 2 NICU admissions due to LBW which was unrelated to the drug administered. Similarly, in the studies conducted by Naga et al and Kaur et al no incidence of adverse Apgar score or NICU admissions were found, hence the drugs were observed to be safe for the fetus in labor. ${ }^{14,15}$

\section{CONCLUSION}

It can, hence, be substantiated that, drotaverine Hydrochloride augments the rate of cervical dilatation 
more than valethamate bromide and reduces the duration of active phase of first stage of labor more effectively. The effects of drotaverine are better without any significant maternal or fetal adverse effects. Drotaverine was found to be a better drug, hence, can be used to reduce the agony of the laboring woman without any significant side effects on the mother or the fetus.

\section{Funding: No funding sources}

Conflict of interest: None declared

Ethical approval: The study was approved by the Institutional Ethics Committee

\section{REFERENCES}

1. Shahul R, Chapman A. Role of drugs in acceleration of normal labor. J Obstet Gynecol. 1984;34:501-4.

2. Brayant WM, Greenwell JE, Weekes PM. Alteration in collagen organization during dilatation of cervix uteri. Surg-Gynae and Obstet 1968; 126(1): 27.

3. Corssen G. A Study of the use and mode of action of the antispasmodic drug Buscopan in gynaecology and obstetrics. Med Klin. 1953;48:1286.

4. Bolaji O. High performance liquid chromatographic method for the determination of drotaverine in human plasma and urine. J Chromato Biomed Appli 1993;622:93-97.

5. Bolaji O, Onyegi CO, Ogundaini AO, Olugbade TA, Ogunbona FA. Pharmacokinetics and bioavailability of drotaverine in humans. Europ J Drug Metab Pharmaco. 1996;21:217-21.

6. Guha N, Lahiri BC. Effect of epidosin on cervical dilatation of labour. Ind Med Gazette. 1984;365-6.

7. Madhu C, Mahavarkar S Bhave S. A randomized controlled study comparing Drotaverine hydrochloride and Valethamate bromide in the augmentation of labour. Arch Gynecol Obstet. 2010;282(1):11-5.

8. Cunnigham FG, Mac Donald PC, Gant NF, Lenevo KJ. Normal labour. Williams's Obstet. 2018;25:430.

9. Sharma M, Singh VK, Upreti S. Diazepam - A valuable drug in labor. J Obstet Gynecol Ind. 1978;579-89.

10. Cheng YW, Shaffer BL, Bryant AS, Caughey AB. Length of the first stage of labor and associated prenatal outcomes in nulliparous women. Obstet Gynecol. 2010;116:1127-35.

11. Vellanki VS. Comparison of hyoscine and valethamate on cervical dilatation in labour. Global $\mathrm{J}$ Med Res. 2010;10(2):18-21.

12. Sharma JB, Pundir P, Kumar A, Murthy NS. Drotaverine hydrochloride v/s Valathamate bromide in acceleration of labour. Int $\mathrm{J}$ Gynae Obst. 2001;74(3):255-60.
13. Nagaria T, Jaiswal J. To compare and evaluate the efficacy and safety of Drotaverine and Valethamate bromide. J Obst Gynae India. 2009;59(4):324-33.

14. Kaur S, Bajwa SK, Kaur P, Bhupal S. To compare the effect of camylofin dihydrochloride (anafortan) with combination of valethamate bromide (epidosin) and hyoscine butyl-n-bromide (buscopan) on cervical dilation. J Clin Diagn Res. 2013;7(9):1897-9.

15. Naga P, Shivanna BS, Subbappa K, Gopal N. Comparative study of efficacy of combination of valethamate bromide and hyoscine with drotaverine hydrochloride on cervical dilatation in active labor. IOSR- JDMS. 2014;13(10):27-9.

16. Kalhon P, Patil AB, Patel R. Efficacy of intramuscular Drotaverine use for cervical dilatation in first stage of labor. Inter $\mathrm{J}$ Recent Trends Sci Technol. 2015;14(3):670-4.

17. Edessy M, El-Aziz A, El-Darwish G, Nasar AAM. Different modalities in first stage enhancement of labor. Gen Health Med Sci. 2015;2:1-4.

18. Patil AB, Kalhon P, Patel R. Comparative study of drotaverine hydrochloride and valethamate bromide in progress of labor. Inter $\mathbf{J}$ Recent Trends Sci Technol. 2015;14(3):678-82.

19. Madhu C, Mahavarkar S, Bhave S. A randomized controlled study comparing Drotaverine hydrochloride and Valethamate bromide in the augmentation of labor. Arch Gynecol Obstet. 2010;282(1):11-5.

20. Rohwer AC, Khondowe O, Young T. Antispasmodic for labor (Review). Cochrane Database of Systematic Reviews. 2013;6:CD009243.

21. Selvaraj SM, Natarajan S. Comparison of Drotaverine hydrochloride and Valethamate bromide on cervical dilatation. J Evolut Med Dent Sci. 2016;5(52):3391-4.

22. Sinhansane H, Nishty GM. A comparative study on the efficacy of drotaverine and valethamate on cervical dilatation during labour. Int $\mathbf{J}$ Reprod Contracept Obstet Gynecol. 2017;6:423-6.

23. Mandal AK, Molla N. Comparison of Drotaverine hydrochloride and Valethamate bromide on cervical dilatation: a hospital based randomized trial. Int J Reprod Contracept Obstet Gynecol. 2018;7:1579-85.

Cite this article as: Deepshikha, Soni M, Gupta D, Godara S. Drotaverine hydrochloride versus valethamate bromide for cervical dilatation in labour: a comparative study. Int J Reprod Contracept Obstet Gynecol 2020;9:1986-91. 